\title{
Skill-biased Technological Change, E-skills and Wage Inequality: Evidence from Tunisia
}

\author{
Najeh Aissaoui and Lobna Ben Hassen
}

Faculty of Economics and Management of Sfax, Tunisia

Correspondence should be addressed to: Najeh Aissaoui; aissaoui.najeh@gmail.com.

Received date: 25 March 2015; Accepted date: 29 June 2015; Published date: 31 August 2016

Academic Editor: Bouras Hela

Copyright (C) 2016. Najeh Aissaoui and Lobna Ben Hassen. Distributed under Creative Commons CCBY 4.0

\begin{abstract}
Although there is a plethora of literature that supports the existence of a technological bias in the US and Europe, exploring such a subject in the developing countries is still relevant and very little processed. This article is part of the perspective that involves examining and bringing additional insight to the phenomenon of the technological change skewed in the Tunisian context. Estimating a multinomial logit model directed to 902 employees generated very original results. First, these results confirm the existence of a technological bias in favour of skilled workers in the Tunisian labour market. However, it is no longer the access or the intensive use of ICT at work that privileges some employees and not others, in terms of pay, but rather the employees' digital skills which contribute to rising inequality. Even more, it is the ability to get, select, process and evaluate information based on the specific needs and capacity to use it to achieve specific objectives, and not the simple manipulation of digital technologies and structures, that are at the core of the problem. Finally, the organizational change also contributes to the amplification of the existing wage disparities. Actually, the more independent the employee is in carrying out his tasks and works per project, the higher the probability of earning a high salary vs low and medium salary. However, several other types of organizations do not have any significant positive effect on the wage rise. This reflects a weakness in the labour organization in the Tunisian firms.
\end{abstract}

Keywords: Skill-biased technological change (SBTC), wage inequality, organizational forms.

\section{Introduction}

The advent of the digital economy through the dissemination of information and communication technology is made mostly responsible for the rising wage inequality. Actually, the recent consensus is based on the fact that the technological change favors the most skilled workers, substitutes the tasks previously carried out by unskilled workers and worsens the existing inequalities (Acemoglu, 2005 ; Card et DiNardo, 2002 ; He et Lui, 2008 ;Winchester et Greenaway, 2007). This opinion was formed through past experience which shows that the arrival of

Cite this Article as: Najeh Aissaoui and Lobna Ben Hassen (2016), " Skill-biased Technological Change, Eskills and Wage Inequality: Evidence from Tunisia ", Journal of Economics Studies and Research, Vol. 2016 (2016), Article ID 492224, DOI: 10.5171/2016.492224 
a new wave of technological innovation in the US had coincided with a considerable rise of inequality between qualifications and within each socio-professional category (Quinet, 2000). This coincidence fueled the argument of a technological bias that can take different versions. Card and DiNardo (2002) suggest two versions of skill-biased technological change: the "rising-skill-price" and "computer-useskill-complementarity". This concept of complementarity had been extremely important in the literature about the technological progress and was used mostly as a theoretical argument that bases the existence of a technological bias (Bartel and Sicherman, 1997; Card and DiNardo, 2002).

The recent widespread worsening of inequality (especially within the nations) causes today a renewed interest for the study of the internal inequality impact on economic growth and the explanatory factors of its increase (Daniel et al., 2015 ; Chan et al., 2014 ; OCDE, 2014 ; Ostry, 2014 ; Javier et Montiel, 2014). This article is part of this perspective in examining the argument of the technological bias in a Tunisian context. The main target of this paper is then to answer the following question:

Do ICTs contribute to widen the pay inequality between skilled and unskilled workers?

Many empirical studies brought an answer to this question for the US and European cases. However, few studies are available on this subject for the Tunisian case (Saafi, 2013; Ghazali, 2009). These studies suffer from several limitations: old data, the use of irrelevant variables to measure the labour skills, the ignorance of the organizational change ... Our contribution is to fill these gaps in data availability using as an investigation technique the survey by a questionnaire. The empirical study of 902 Tunisian workers belonging to three sectors (manufacturing, administrative and service) and living in Tunis and Sfax resulted in very original results.

This paper is organized as follows. The next section is devoted to a literature review. The third section traces some descriptive statistics on the labor market and the Tunisian ICT sector. In section four, we present our research methodology, including the data collection method, the sample characteristics, the used variables, and our econometric modeling. Section five is about the estimation results and their economic interpretation. Finally, there is the conclusion.

\section{Literature review}

Historically, technological change and inequality have often been regarded as two independent, separate and opposite processes. Inequality is one of the biggest problems that the world (including the developing countries) is facing today whereas technology is the engine of economic growth. However, the coincidence of the arrival of a new wave of technological innovation in the United States with a considerable increase of wage inequality between qualifications in the $80 \mathrm{~s}$, made the ICT the main responsible for this rise and raised the argument of the technological bias (Quinet, 2000). Having examined the relationship between growth, inequality and globalization, Aghion and Williamson (1998) pointed out that technological change is the most important element in explaining the dynamics of internal inequalities within nations. Acemoglu (2001) argues that in the United States, the relative supply of skills has increased rapidly during the past 60 years; however, there was no decline in the return to education corresponding to this growth, but a rise of the premium skills during this period. He explains this trend by the fact that new technologies, in the period after the war, were skill-biased. In the same vein, Card and DiNardo (2002) argue that the SBTC exists when changes in the relative wages are not inversely related to changes in the relative supply. Introducing new technologies in the process of production and in the companies' operating system usually leads these companies to recruit more educated workforce to the detriment of the less educated. The plausible explanation is that skilled workers are more likely to adopt and implement new technologies within firms. Consequently, ICT is said to be biased in favour of skilled labor. He and Liu (2008) examined the 
quantitative importance of the investmentspecific technological change (ISCT) in explaining the wage inequality dynamics and the accumulation of skills using a general equilibrium model. These authors argue that if the investment-specific technological change increases, the relative price of capital equipment decreases, which encourages investment in new technology. Considering the hypothesis of equipmentskill complementarity, and due to the increase of the capital equipment stock, the accumulation of skills will be encouraged and there will be an increase in the marginal productivity of skilled workers at the expense of the unskilled ones. As a result, the wage premium will change. Several empirical studies support the hypothesis of skill-biased technological change for the US case and show that technology can substitute the less qualified workers and intensify the existing pay inequality between the two categories of employees (Acemoglu 2005; Card and DiNardo 2002. He and Lui 2008; Greenaway and Winchester 2007).

The skill challenge is at the core of the skillbiased technological change hypothesis. Brotcorne and Valenduc (2009) stipulate that the qualification and cognitive abilities of individuals affect the use of ICT and the exploitation of its content. The acquisition and mobilization of a series of specific skills help tackle the ICT and digitized information issue. On his part, De Haan (2003) argues that "social inequalities are not primarily an issue of having a PC or Internet access. Today, and even more in the future, the uses of ICT and digital skill level decide who is ahead, who follows and who remains behind in the society of information. More specifically, it is the impact of the use of ICT and digital skills in various domains of social life which is at the heart of the problem. The growing importance of ICT in these areas contributes to deepening inequality and marginalization of the excluded."2 Van Deursen and van Dijk (2010) distinguish between four types of digital skills: operational skills, which are the skills for managing digital technologies, formal skills, which are the skills to manipulate the structures of digital technology, information skills, which are the skills to locate information in the digital media, and strategic skills, which are the skills to use the information contained in the digital media to achieve specific objectives and improve one's position in the society.

For Green (1996), the technological bias, in a large part, would be organizational. Indeed, the introduction of ICT by firms enhances them to adopt organizational changes in all dimensions: their internal architecture, their borders and their relationships with the outside (Benghozi and Cohendet, 1997). Because qualified employees in reorganized companies are offered more interesting and better-paid jobs (Caroli and Van Reenen, 2001), wage inequality can be considerably increased. Therefore, organizational change is also biased in favor of skilled labor. Black and Lynch (2001) show that work organization has led to an increase of wages by $6 \%$ to $14 \%$ in the 1980s in the United States. Likewise, Black et al. (2003) certify the existence of strong correlations between the adoption of new organizational forms and the rise of inequality within companies. However, the effect of organizational change on wage inequality remains ambiguous (Greenan, 1996) since the level of remuneration is often high in companies that are implementing additional measures, such as computerization. A further econometric analysis put forward by Bauer and Bender (2002) shows that in Germany, organizational change destroys jobs for low and medium skilled workers but does not affect the working conditions of the more qualified ones.

Therefore, work organization discriminates against low-skilled workers by lowering their wages if the labor market is flexible, and by raising their unemployment share if there is some rigidity. Crifo (2003) states that the recent changes in the equipment (multi-purpose machine tools, programmable and flexible equipment, computer-assisted programming, ....) facilitate the employees' job rotation and reduce the labor requirements allocated to repetitive tasks. As a result, companies that adopt technological innovations are also using new organizational forms, however, only firms that adopt both these two types of innovation (technological and organizational) achieve productivity gains 
(Bresnahan et al. 2002; Askenazy and Gianella, 2000). In the same vein, Bué et al. (2002) suggest that the effects of new technologies on the skills would rather be to look into new forms of organizations promoted by these technologies. Greenan and Walkowlak (2005) examined the complementarity between the new technology and the work organization for various trade groups. More particularly, they showed that the distribution of automatic machines is accompanied by a more workers' autonomy and more communication.

Some stylized facts: ICT diffusion and skill development in the Tunisian labor market

Tunisia, like most countries in the MENA zone, is a technology-consumer country which shows today a great lag behind the developed countries in terms of invention and technological innovation. There are many obstacles to the activity of technological innovation in this country, for example, the high costs, the quality of human capital, which is rather average, the inadequate skills, the poor infrastructure, the lack of financial resources, the organizational rigidity within companies and institutions ... This has caused a relatively low technological potential for Tunisia and increased its dependence on foreign technologies.

\section{Skill evolution}

Since 1990, the overall employment in Tunisia has been increasing (see Table 1) despite the slowdown of the population growth. This rise is mainly due to the increase of female participation in the labor market which rose from $20.9 \%$ in 1990 to $25.1 \%$ in 2012 .

Table 1: The growth of employment and participation rates of female labor in Tunisia

\begin{tabular}{|l|l|l|l|l|l|l|}
\hline & $\mathbf{1 9 9 0}$ & $\mathbf{1 9 9 5}$ & $\mathbf{2 0 0 0}$ & $\mathbf{2 0 0 5}$ & $\mathbf{2 0 1 0}$ & $\mathbf{2 0 1 2}$ \\
\hline Total employment & 24.536 .08 & 28.523 .59 & 32.008 .64 & 34.315 .66 & 38.013 .52 & 39.304 .59 \\
\hline $\begin{array}{l}\text { Rates of working } \\
\text { women (\%) }\end{array}$ & 20,9 & 22,8 & 23,8 & 24,3 & 24,9 & 25,1 \\
\hline
\end{tabular}

Source: The author using data from the World Bank

Moreover, as shown in Figure 1 below, there is a trend towards the qualification of the workforce on the Tunisian labor market. In fact, the proportion of the labor force having a university degree rose from $1.2 \%$ in 1966 to $7 \%$ in 1994 to reach $17 \%$ in 2011. Furthermore, the proportion of the workers who have a secondary or vocational education degree in the total employment showed a remarkable increase. It should be noted, however, that during this same period, the proportion of unskilled labor has been falling rapidly and continuously. 


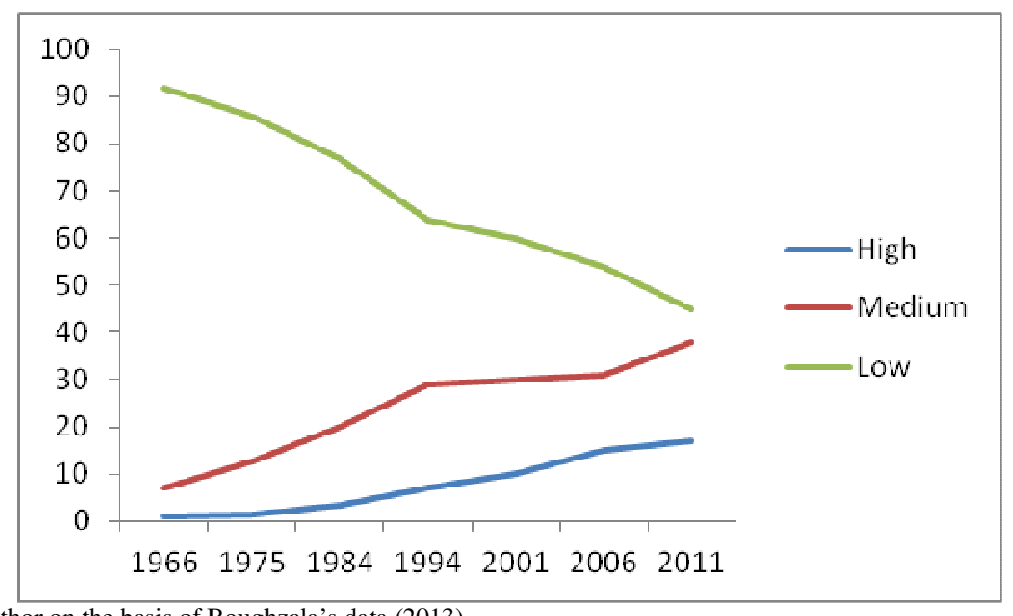

Source: The author on the basis of Boughzala's data (2013)

Figure 1: The evolution of the Tunisian workforce by qualification

\section{A review of the Tunisian national potential in ICT}

The increase of skilled labor in Tunisia is followed by a rapid change in the access to and the use of ICT.

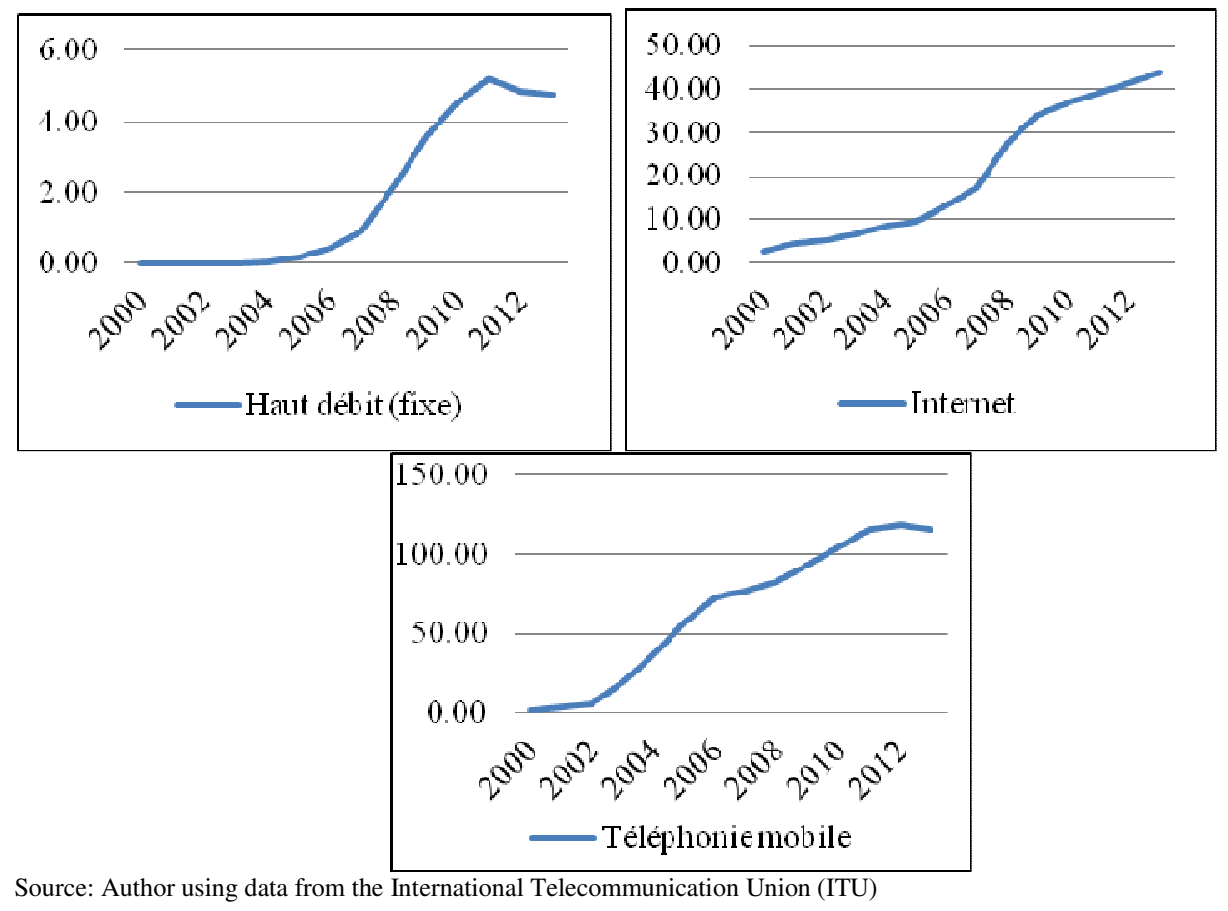

Figure2: The evolution of access and use of some ICT in Tunisia between 2000 and 2013

Actually, the penetration of the mobile telephony (per 100 inhabitants), which was less than 2 in 2000, exceeded 115 in 2013. The rate of use of the Internet by the Tunisians went from less than 3\% in 2000 to more than $40 \%$ in 2013 . Moreover, the penetration rate of fixed broadband (per 100 inhabitants), which had been 0 until 2004, exceeded 5 in 2011 (Figure 2). 
Table 2: The correlation between the ICT indicators and the evolution of qualifications in the Tunisian labor market between 2006 and 2011

\begin{tabular}{|l|c|}
\hline & Main d'euvre qualifiée \\
\hline Internet use & 0.9636 \\
\hline Penetration of Broadband (fixe) & 0.9905 \\
\hline Penetration of mobile phone & 0.9912 \\
\hline Source: The author using data from the World Bank (WB)
\end{tabular}

Table 2 shows strong correlations between the technological indicators mentioned above and the rise of the skilled labor number in the Tunisian labor market during 2006-2011.

Imports of capital equipment are considered by some authors, (Conte and Vivarelli, 2007), as a factor underling the rise of the number of educated workers and the decrease of that of the unskilled ones in the developing countries. In Tunisia, for example, they knew remarkable fluctuations during the 20002007 period with a steady growth since 2008 (Figure 3). These imports come mainly from France, Germany and Italy.

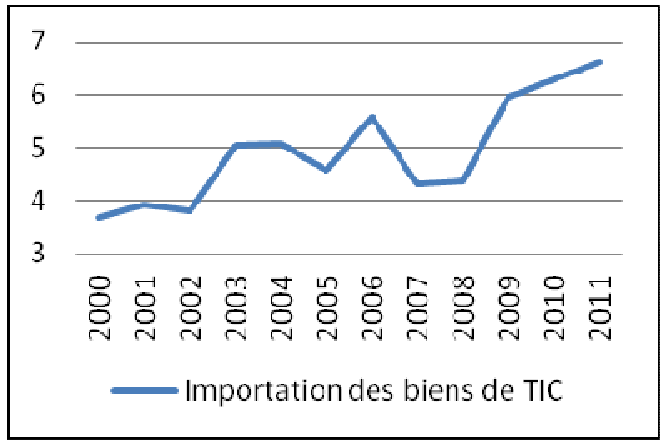

Source: The author on the basis of the World Bank data

Figure 3: the evolution of the proportion of ICT imports in the total imports in Tunisia

Like most developing countries, Tunisia follows a set of successive sequences in the technology diffusion process that begins with the importation of standardized technologies, imitation, adaptation, processing and export of intermediate technology. Exports of ICT goods were about $7 \%$ of the overall exports of goods in 2011.

The proportion of ICT investment is (relatively) still low despite the increase recorded in recent years. In fact, it rose from about $4 \%$ in 2000 to $5.4 \%$ in 2008 . According to Foulkes and Howitt (2002), in the developing countries, investment in ICT is necessary in order to understand and adopt foreign technologies, which are often circumstantial and tacit, to the local environment.

\section{Methodology}

It should be recalled that the goal of our research is to find out if there is a technological bias in Tunisia for the most qualified employees. More specifically, our problem is as follows: can we establish a link between the qualifications, the use of ICT, and the pay level?

\section{Data collection method}

Being conditioned by the availability of data, we used, as an investigation technique, the questionnaire survey to achieve our research objective. We proceeded through a twenty-question questionnaire which reflects the main concerns of our research of analyzing our problem. Most of the collected information is qualitative whereas the rest is 
quantitative. It should be noted, however, that the development of the questionnaire is based on an extensive review of theoretical and empirical literature.

The questionnaire delivery procedure took place throughout 2014. To distribute the questionnaire, we opted for three delivery mechanisms. The first is a direct distribution of the questionnaire. The advantage of this mode is that it gives explanations and clarifications on the matters when necessary and therefore it ensures better response quality. It can also make the response time short. The second mode is a self-conduct questionnaire: the questionnaire is handed to a company official who, in turn, takes the responsibility of distributing it. The last mode of the questionnaire conduction is to transfer it electronically. This helped us distribute 1,000 copies 902 of which were usable, with a rate of $90.2 \%$. Our questionnaire consists of five parts. The purpose of the first part is to collect information about the employee's characteristics and the company where he works. The second part is about the employee's access and use of ICT at work. The third part is devoted to the evaluation of his digital skills. The fourth part is about the new organizational forms in which employees are involved. The last part of the questionnaire is devoted to the wages.

\section{The sample characteristics and the variables}

The final sample includes 902 employees belonging to the service, administrative and industrial sectors. The descriptive statistics of the variables are presented in Table 3. $35.37 \%$ of the surveyed employees belong to the industrial sector, $39.14 \%$ to service sector and $25.5 \%$ to the administrative sector. About $11 \%$ of the respondents have a secondary school education, $23.61 \%$ have a university undergraduate degree, $41.91 \%$ are graduates and $23.73 \%$ postgraduates. $49.56 \%$ of the employees in our sample are female against $50.44 \%$ male. More than
$40 \%$ of the sample employees have less than 5 years of professional experience, $43.68 \%$ have between 5 and 20 years and $15.74 \%$ have more than 20 years. Approximately, $34 \%$ are less than 30 years of age, $42.46 \%$ between 30 and 40 years old and $23.28 \%$ are over 40 . About $17 \%$ of companies in which employees work are micro-businesses (fewer than 10 employees), $29 \%$ of small companies (10 to 50 employees) and $54.32 \%$ of medium and large businesses (over 50 employees).

Four sets of explanatory variables are used for this study. The first includes the predictors related to the employee's characteristics and the business in which he works: sex, age, education level, work experience, training, company's operating sector, and size. These characteristics are often raised in the literature as explanatory factors of salary and pay differences (eg Mincer, 1974; INSEE, 2010). The second set of variables contains the variables related to the access to the ICT, its use and intensive use in the workplace: the use of the telephone, computer, laptop, other hardware, software, internet, intranet, the use intensity (number of hours) and experience in ICT at work. As we have seen in the theoretical part of this study, there is a developed overabundant literature today which agrees that technological change contributes to amplify the pay differences between the different types of qualification. We would like to test this hypothesis using this second set and a third one that includes variables measuring the employee's digital skills which were assessed by referring to a typology presented by Van Deursen and van Dijk (2010) who distinguish four levels of digital skills: operational, formal, informational and strategic skills. The last series includes variables related to new organizational forms in which the employee is involved: teamwork, job rotation, participation in decision making, task flexibility (or autonomy), cooperation, project work and versatility. 
Table 3: Descriptive statistics

\begin{tabular}{|c|c|c|c|c|c|}
\hline & Obs & Mean & $\begin{array}{l}\text { Standard } \\
\text { deviation }\end{array}$ & Min & Max \\
\hline \multicolumn{6}{|c|}{ Employee's characteristics } \\
\hline Gender & 902 & 0,5044 & 0,5003 & 0 & 1 \\
\hline Age & 902 & 0,8902 & 0,7510 & 0 & 2 \\
\hline Position & 902 & 0,5532 & 0,6671 & 0 & 2 \\
\hline Education & 902 & 1,7860 & 0,9267 & 0 & 3 \\
\hline Work experience & 902 & 0,7517 & 0,7086 & 0 & 2 \\
\hline Training & 902 & 0,6330 & 0,4822 & 0 & 1 \\
\hline \multicolumn{6}{|c|}{ Company's characteristics } \\
\hline Sector & 902 & 0,9013 & 0,7743 & 0 & 2 \\
\hline Size & 902 & 1,3769 & 0,7537 & 0 & 2 \\
\hline \multicolumn{6}{|c|}{ Use and its intensity use of ICT } \\
\hline Tel & 901 & 2,1842 & 1,4543 & 0 & 4 \\
\hline Computer & 900 & 2,6367 & 1,5182 & 0 & 4 \\
\hline Laptop & 902 & 1,1696 & 1,5841 & 0 & 4 \\
\hline Others & 902 & 1,6530 & 1,4508 & 0 & 4 \\
\hline Software & 900 & 1,9189 & 1,7474 & 0 & 4 \\
\hline Internet & 902 & 2,1619 & 1,6545 & 0 & 4 \\
\hline Intranet & 901 & 2,0189 & 1,7463 & 0 & 4 \\
\hline Intensity use & 902 & 1,8736 & 1,0070 & 0 & 3 \\
\hline Experience with ICT & 902 & 1,4557 & 0,7910 & 0 & 2 \\
\hline \multicolumn{6}{|l|}{ E-skills } \\
\hline Operational skills & 902 & 6,5898 & 2,4967 & 0 & 9 \\
\hline Formal skills & 900 & 5,4822 & 2,7569 & 0 & 10 \\
\hline Information skills & 902 & 4,4379 & 2,2149 & 0 & 7 \\
\hline Strategic skills & 902 & 2,6818 & 1,8933 & 0 & 6 \\
\hline \multicolumn{6}{|l|}{ Organizational forms } \\
\hline Teamwork & 902 & 1,8991 & 1,0978 & 0 & 3 \\
\hline Job rotation & 902 & 0,5854 & 0,6687 & 0 & 2 \\
\hline Participation & 901 & 0,6670 & 0,4786 & 0 & 2 \\
\hline Flexibility & 902 & 1,4335 & 0,7326 & 0 & 2 \\
\hline Cooperation & 901 & 2,7125 & 1,3024 & 0 & 5 \\
\hline Project work & 900 & 0,4956 & 0,5531 & 0 & 5 \\
\hline Polyvalence & 902 & 1,4634 & 0,8351 & 0 & 3 \\
\hline Salary & 898 & 1,1013 & 0,6954 & 0 & 2 \\
\hline
\end{tabular}




\section{Econometric methodology}

To test the skill-biased technological change hypothesis, we chose the salary's indigenization approach reported in the literature. We will analyze the impact of the employee's various characteristics and the company where he works, his use of ICT at work, his digital skills and involvement in new organizational forms on the salary. This latter is unobservable and only his belonging to one of the three categories is observed:

\section{0 if the salary is less than $600 \mathrm{TD}$ $\{1$ if the salary is between 600 and $1200 \mathrm{TD}$ 2 if the salary is more than $1200 \mathrm{TD}$}

Given the nature of the variables, we opted for an ordered multinomial logit model. This consists in modeling not the dependent variable itself but rather its likelihood of having values 0,1 , or 2 . A multinomial logit model neglects the ordinality of the dependent variable; however, the linear regression deals with the difference between indices 2 and 3 in the same manner as the difference between
0 and 1 although this corresponds only to a ranking. As a result, these two estimators would be biased.

One way of modeling the problem, where the dependent variable is an ordered multinomial variable, is the assumption that there is a latent (unobserved continuous) variable such that:

$$
y\left\{\begin{array}{l}
0 \text { if } y_{n}{ }^{4}<c_{0} \\
1 \text { if } c_{0}<y_{n}^{*}<c_{1} \\
2 \text { if } y_{n}>c_{1}
\end{array}\right.
$$

Where $c_{\text {f }}$ are the unknown bounds to estimate, which define the frontier intervals in which the latent variable may exist. Then, we assume that the latent variable is a linear combination of the explanatory variables:

$$
y_{i}^{*}=x_{i}^{n} \beta+u_{i}
$$

With $y_{i}$ "is the unobserved measure of the

vector and $\pi_{I_{i}}$ the residual error that employee's salary, $x_{i}^{\prime}$ the vector of the follows a logistic distribution ${ }^{2}$.

The likelihood of occurrence of each index explanatory variables, $\beta$ the parameter of our dependent variable is given by:

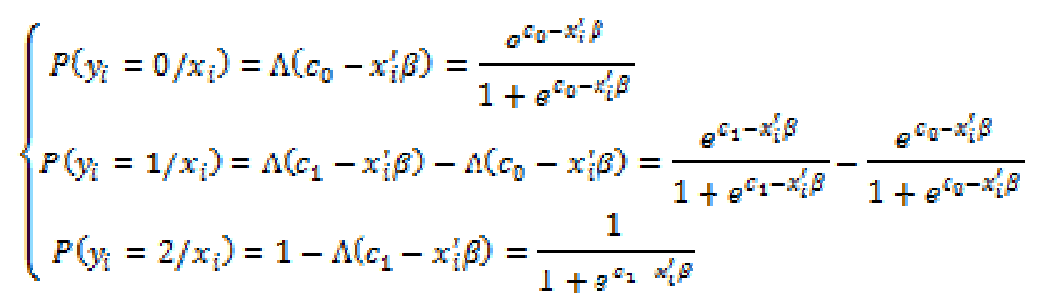


With $\mathbf{A}$ representing the distribution function of the logistic. The method generally used to estimate these models is the maximum likelihood. The likelihood equations form a nonlinear equation system in $\beta$. The resolution of this system is made by means of a numerical optimization algorithm. The econometric software uses either the Newton-Raphson method or the Score method.

\section{Results and interpretations}

Setting up a multinomial ordered logit model implies that the hypothesis of the equality of slopes (proportionality assumption) is maintained. This means that the distance between the categories of the dependent variable is proportional, which is rarely verified in practice. The application of the likelihood ratio test and/or Brant test can help examine the assumption of proportional odds ${ }^{3}$. Regarding our model, both tests are significant hence; the proportional odds assumption is violated. In this case, we have to choose between four options. First, to do nothing, that is, using a multinomial ordered logit since the practical implications of violating this assumption are minimal. Second, use a multinomial logit which frees us from the assumption of proportionality. However, the latter ignores ordinality of the dependent variable, less parsimonious and often questionable substance. The third option consists in dichotomizing the dependent variable and using binary logistic regression; however, we lose information and could change our substantive conclusions. Finally, we use a generalized ordered logit model that does not undertake proportionality.

Ultimately, we chose to estimate an ordered logit model since it could provide more information about the explanatory factor variables. The empirical results for the estimated ordered multinomial logit model, the odds ratios and marginal effects are reported in Table 4 . The model loglikelihood value is equal to -587.17 . The Wald test (which is equivalent to the likelihood ratio test) is significant at $0.1 \%$. This test confirms that all the slope coefficients are significantly different from 0 .

Table 4: Results, odds ratios and marginal effects from the ordered multinomial logit model

\begin{tabular}{|c|c|c|c|c|c|c|}
\hline \multirow{2}{*}{\multicolumn{2}{|c|}{$\begin{array}{l}\text { Dependent variable: Wage } \\
\text { Independent variables }\end{array}$}} & \multirow{2}{*}{ Coefficient } & \multirow{2}{*}{$\begin{array}{l}\text { Odds } \\
\text { Ratio }\end{array}$} & \multicolumn{3}{|c|}{ Marginal effects } \\
\hline & & & & $\leq 600 \mathrm{DT}$ & {$[600,1200]$} & $\geq 1200 \mathrm{DT}$ \\
\hline \multicolumn{7}{|c|}{ Employee characteristics' } \\
\hline \multirow[t]{2}{*}{ Gender } & Female & Ref. & Ref. & - & - & - \\
\hline & Male & $0.7307 * * *(0.1746)$ & $2.0765 * * *$ & $-0.0541 * * *$ & $-0.0544 * * *$ & $0.1085 * * *$ \\
\hline Age & - & - & _- & $-0.0444 * * *$ & $-0.0459 * * *$ & $0.0903 * * *$ \\
\hline $\mathbf{0}$ & $<30$ years & Ref. & Ref. & - & - & - \\
\hline 1 & {$[30,40]$} & $0.6636 * * *(0.2330)$ & $1.9418 * * *$ & _- & _- & _- \\
\hline 2 & $>40$ years & $1.2416 * * *(0.3330)$ & $3.4611 * * *$ & _- & _- & _- \\
\hline Education & - & - & - & $-0.0303 * * *$ & $-0.0313 * * *$ & $0.0617 * * *$ \\
\hline 0 & Secondary & Ref. & Ref. & - & - & - \\
\hline 1 & Undergraduate & $0.5618(0.3653)$ & $1.7538^{*}$ & $\ldots$ & $\ldots$ & $\ldots$ \\
\hline 2 & Graduate & $0.9773 * * *(0.3675)$ & $2.6573 * * *$ & - & - & - \\
\hline 3 & Postgraduate & $1.5021 * * *(0.4204)$ & $4.4909 * * *$ & - & _- & _- \\
\hline $\begin{array}{c}\text { Prof. } \\
\text { experience }\end{array}$ & - & - & - & $-0.0442 * * *$ & $-0.0457 * * *$ & $0.0899 * * *$ \\
\hline 0 & $<5$ years & Ref. & Ref. & - & - & - \\
\hline 1 & {$[5,20]$} & $0.4350 *(0.2361)$ & $1.5450 *$ & - & _- & _ \\
\hline
\end{tabular}




\begin{tabular}{|c|c|c|c|c|c|c|}
\hline 2 & $>20$ years & $1.5405^{* * *}(0.4028)$ & $4.6668 * * *$ & - & - & - \\
\hline Training & - & $-0.0396(0.1722)$ & 0.9612 & 0.0038 & 0.0040 & -0.0078 \\
\hline \multicolumn{7}{|c|}{ Campany characteristics' } \\
\hline Sector & _- & - & & 0.0037 & 0.0038 & -0.0076 \\
\hline $\mathbf{0}$ & Service & Ref. & Ref. & - & - & - \\
\hline 1 & Industrial & $0.4860 * *(0.2194)$ & $1.6258 * *$ & _- & _- & _- \\
\hline 2 & Administrative & $-0.1512(0.2486)$ & 0.8597 & - & - & _- \\
\hline Size & _- & _- & _- & $-0.0548 * * *$ & $-0.0566 * * *$ & $0.1114 * * *$ \\
\hline $\mathbf{0}$ & $<10$ & Ref. & Ref. & - & - & - \\
\hline 1 & {$[10,50]$} & 0.8386 *** $(0.2703)$ & $2.3131 * * *$ & - & _- & - \\
\hline 2 & $>50$ & $1.4629 * * *(0.2799)$ & $4.3183 * * *$ & - & - & - \\
\hline \multicolumn{7}{|c|}{ Use and intensity of use of ICT } \\
\hline Tel & _- & $-0.1202 *(0.0662)$ & $0.8867 *$ & $0.0082 *$ & $0.0085^{*}$ & $-0.0167 *$ \\
\hline Computer & - & $-0.0398(0.0714)$ & 0.9610 & 0.0010 & 0.0010 & -0.0021 \\
\hline Laptop & - & $0.0987(0.0676)$ & 1.1037 & $-0.0088 *$ & $-0.0091 *$ & $0.0180^{*}$ \\
\hline Others & _ & $0.0387(0.0710)$ & 1.0394 & -0.0031 & -0.0032 & 0.0063 \\
\hline Software & _- & $0.0807(0.0642)$ & 1.0841 & $-0.0077 *$ & $-0.0079 *$ & $0.0156^{*}$ \\
\hline Internet & - & $-0.2252 * * *(0.0634)$ & $0.7983 * * *$ & $0.0135^{* * *}$ & $0.0139 * * *$ & $-0.0274 * * *$ \\
\hline Intranet & - & $0.1865 * * *(0.0622)$ & $1.2050 * * *$ & $-0.0135 * * *$ & $-0.0140 * * *$ & $0.0275 * * *$ \\
\hline $\begin{array}{c}\text { Intensity of } \\
\text { use }\end{array}$ & & - & - & -0.0064 & -0.0066 & 0.0130 \\
\hline $\mathbf{0}$ & $<$ à $2 \mathrm{~h}$ & Ref. & Ref. & - & _- & - \\
\hline 1 & {$[2,4]$} & $-0.6467 * *(0.2775)$ & $0.5238 * *$ & _- & - & _- \\
\hline 2 & {$[4,8]$} & $0.2421(0.2842)$ & 1.2740 & - & _- & _- \\
\hline 3 & $>$ à $8 \mathrm{~h}$ & $-0.0377(0.3170)$ & 0.9630 & - & - & - \\
\hline $\begin{array}{l}\text { Experience } \\
\text { with ICT }\end{array}$ & - & - & - & -0.0024 & -0.0025 & 0.0048 \\
\hline $\mathbf{0}$ & $<$ à 5 years & Ref. & Ref. & - & - & - \\
\hline 1 & {$[2,5]$} & $-0.0702(0.2717)$ & 0.9322 & - & - & - \\
\hline 2 & $>5$ years & $0.1547(0.2464)$ & 1.1673 & - & - & - \\
\hline \multicolumn{7}{|c|}{ E-skills } \\
\hline Operational & - & $0.0412(0.0539)$ & 1.0421 & -0.0040 & -0.0041 & 0.0081 \\
\hline Formal & - & $0.0466(0.0603)$ & 1.0477 & -0.0034 & -0.0035 & 0.0069 \\
\hline Informational & - & $0.2452 * * *(0.0636)$ & $1.2779 * * *$ & $-0.0152 * * *$ & $-0.0157 * * *$ & $0.0309 * * *$ \\
\hline Strategic & - & $0.1426 * *(0.0675)$ & $1.1533^{* *}$ & $-0.0086^{*}$ & $-0.0089 *$ & $0.0174 *$ \\
\hline \multicolumn{7}{|c|}{ Organizational Forms } \\
\hline Teamwork & - & $-0.0856(0.0779)$ & 0.9180 & 0.0066 & 0.0068 & -0.0135 \\
\hline Job rotation & - & $0.0742(0.1311)$ & 1.0770 & -0.0012 & -0.0012 & 0.0024 \\
\hline Participation & _- & $-0.1554(0.1829)$ & 0.8561 & 0.0109 & 0.0113 & -0.0222 \\
\hline Flexibility & - & $0.2466^{* *}(0.1240)$ & $1.2797 * *$ & $-0.0183^{* *}$ & $-0.0189 * *$ & $0.0372 * *$ \\
\hline Cooperation & - & $-0.0020(0.0645)$ & 0.9980 & -0.0010 & -0.0010 & 0.0020 \\
\hline Project work & _- & $0.7129 * * *(0.1526)$ & $2.0400 * * *$ & $-0.0477 * * *$ & $-0.0493 * * *$ & $0.0970 * * *$ \\
\hline polyvalence & _- & $0.4473 * * *(0.1115)$ & $1.5641 * * *$ & $-0.0305 * * *$ & $-0.0315 * * *$ & $0.0621 * * *$ \\
\hline
\end{tabular}

The estimated parameters indicate the impact of a one-unit change in the explanatory variables on the log of the odds ratios. The results show that the employee's characteristics and those of the company in which they operate, the access and use of ICT at work, the e-skills and the involvement of the employee in new 
organizational forms are discriminating in classifying the employee in a different wage category.

Table 4 shows that the probability of receiving high salary versus average and low salary estimated for male employees is 2.07 , which means that being a man raises the probability of receiving a high salary rather than a medium and low salary by twice. In Tunisia, women's participation in the labor market is still lower than men's. Their incomes contribute to the household budget as a complement rather than a main income. Thus, they tend to accept lower wages than men. Using Turkish data, Calavrezo and Pelek (2011) support this idea by showing that being a man reduces the likelihood of receiving a minimum wage.

The employee's age and experience strongly act in favor of higher remuneration. Compared to young employees, being aged between 30 and 40 years (over 40 years) increases the chance of earning a high salary vs low and average salary by $94 \%$ (3 times). Professional experience has a similar impact. Hence, an increase by one unit reduces the probability of receiving low wage by about $3 \%$ and raises the probability of earning a high salary by about $6 \%$.

The results also show that education plays a discriminating role in wage determination. The higher educational level is, the more likely to earn high wages. In fact, compared to a high school graduate, a college graduate or post-graduate employee has respectively twice or 4 times as much chance to access a higher salary than a low and average salary. This result is consistent with the economic theory which states that the most skilled workers are better paid, which backs up the existence of a technological bias in favor of skilled workers.

Some features of the firm in which the employee works significantly affect his salary. Therefore, unlike in the administrative sector, working in industry or service sectors raises the employee's chance of earning a higher pay. It is also clear that, compared to micro-enterprises, working in small and medium enterprises increases the odds ratio by respectively 2 and 4 times to earn a higher salary vs medium and low.

Table 4 also shows that apart from the use of intranet, which shows a highly significant positive impact, the access and intensity of using ICT at work admit no favorable significant effect on the wage development. The odds ratios of high salary versus low and medium salary estimated for the variables telephone and Internet are of about 0.8 , which means that the use of the telephone or the Internet by employees at work reduces the odds by $20 \%$. Moreover, an increase in the intensity of the computer and the Internet use (between 2 and 5 hours) reduces by $48 \%$ the chance of earning a high salary versus medium and small salary, compared with the use intensity of less than 2 hours per day. This unexpected result is essentially due to the nature of use of these technologies in the workplace and even to that of the work performed by the employee. Actually, when conducting the questionnaire, it appeared that the secretaries and office workers are those who use the phone and the computer more intensively at work whereas the Internet is generally used for leisure (Facebook, Twitter ...) and not for professional reasons. Neither experience in the use of ICT at work, nor the use of the computer (fixed and mobile) and other IT tools will have a significant effect on the evolution of wages.

However, the estimation of our model revealed a positive and significant effect of informational and strategic digital skills on the likelihood of access to high wages (3.1\% and $1.7 \%$, respectively). An increase of one unit of the employees' information skills (strategic) improves the odds of high wages versus low and medium by 1.28 (1.15), which means an increase of the probability by $28 \%$ (15\%). However, no significant effect was detected for the operational and formal skills on the wage development. This may confirm that, today, wage inequalities caused by the ICT in Tunisia are not an issue of operational and structural manipulation of the hardware and network, but rather a matter of 
selection, evaluation and use of digital information in a relevant way in order to act on one's professional life.

Finally, some organizational forms have a positive and highly significant effect on the probability that the employee is classified in a pay grade. The more independent the employee is in carrying out his tasks, the higher the probability of earning a high salary will be. In fact, an increase of one unit of task flexibility improves the odds ratio estimated to reach a higher salary versus low and medium salary of 1.28 , which implies an increase of the probability by $28 \%$. Moreover, an increase by a unit of work per project raises the likelihood of having a high salary by about $10 \%$ and reduces the probability of earning a low or medium salary of about $5 \%$. Therefore, the dissemination of ICT in the Tunisian firms created a growing need for a more flexible labor force and imposed new requirements for autonomy, selforganization and management tensions. The employee's involvement in other organizational forms, such as teamwork, job rotation, participation in decision making and cooperation, shows no effect on the evolution of his salary. In Tunisian firms, teamwork and cooperation are often observed among employees, whereas participation in the decision making and job rotation are not quite common organizational forms.

To summarize, the fact that the educational level (1st and 2nd cycle university degree) has a positive and a highly significant effect on the probability of earning a high salary means that the wage gap between the two categories of labor (skilled and unskilled) is beginning to amplify. However, a nonsignificant overall effect on the access and use of ICT at work raised doubts about the origin of this bias against the less qualified. The highly significant favorable impact of digital skills on the wage development comes to remove these doubts and confirm the existence of a technological bias for the benefit of the more educated workers in Tunisia. It must be said as well that it is not the access or the intensive use of ICT at work that favors some employees compared to others regarding the pay, but it is rather the quality of using the ICT and digital skills of the employee, which accentuates the disparities. Even more, it is the ability to search, select, process and evaluate information based on specific needs and the capacity of using it to achieve specific objectives and improving its position in the company that are at the core of the problem, and not the simple manipulation of digital technology and its structures.

\section{Conclusion}

The objective of this article is to examine the impact of ICT on the intra-national inequality and particularly on the wage inequality between the different types of qualifications in a Tunisian context and based on the skill-biased Technological Change hypothesis. The starting point of this analysis is intended to provide a theoretical framework analysis for the phenomenon of the SBTC. Then, after having made some descriptive statistics about the labor market and the diffusion of ICT in Tunisia, we opted for a salary modeling approach to check the existence of a technological bias on the Tunisian labor market. The main results revealed from the estimation of a multinomial ordered logit model on 902 employees working in the industrial, administrative and service sectors are the following.

First of all, the employees' cognitive skills are a discriminating factor in explaining wage inequality. In fact, an increase in the educational level raises the employee's chances to access higher wage categories. In addition, greater informational and strategic digital skills entail a higher probability of reaching a higher salary. These results confirm the existence of a technological bias in favor of the better educated on the Tunisian labor market. Then, access and intensity of the ICT use in the workplace do not have a favorable significant effect on the wage development. This means that it is not only the access or intensive use of ICT at work that favors some employees instead of others regarding the wage level, but rather the quality of the ICT use and the employees' digital skills that contribute to the worsening of inequalities. More fundamentally, it is the ability to search, 
select, process and evaluate information based on specific needs and capacity to use it in achieving one's specific objectives and improve one's position in the company that are at the heart of the problem, rather than the simple manipulation of digital technology and its structures.

Finally, some organizational forms also contribute to the deepening of the existing wage inequalities. In fact, the likelihood of earning a high versus low and medium salary is so high that the employee is independent in performing his tasks and that he works per project. However, several other types of organizations (teamwork, job rotation, participation in decision making, cooperation) have no significant effect on the evolution of wages. This reflects a weakness in the organizational work in the Tunisian firms. However, as stated by M'Henni and Methamem (2008), ICT investment will be counter-productive if it is not accompanied by organizational change. In this regard, we believe that policy makers and companies' management should pay more attention to the work organization within firms. Moreover, we highlight the importance of establishing a training system in the field of ICT to improve the employees' digital skills and then fight the amplification of pay inequalities that might result from the diffusion of the ICTs and work organization.

\section{Notes:}

1 Valenduc and Vendramin (2004)

2 Since we opted for a logit model.

3 The null hypothesis assumes that there is no difference in the coefficients between models.

\section{References}

1. Acemoglu, 2001. Directed Technical Change. NBER Working Pape, Issue 8287.

2. Acemoglu, D., 1998. Why Do New Technologies Complement Skills? Directed Technical Change and Wage Inequality. The Quarterly Journal of Economics, 113(4), pp. 1055-1089.
3. Acemoglu, D., 2007. Equilibrium bias of technology. Econometrica, 75(5), p. 13711409.

4. Aghion, P. \& Williamson, J. C., 1998. Growth, Inequality and Globalization: Theory, History and Policy. New York and Cambridge: Cambridge University Press.

5. Askenazy, P. \& Gianella, C., 2000. Le paradoxe de la productivité: les changements organisationnels, facteur complémentaire à l'informatisation. Economie et Statistiques, Issue 339-340, pp. 219-242.

6. Bartel, A. P. \& Sicherman, N., 1997. Technological Change and Wages: An interIndustry analysis. NBER Working Paper, Issue 5941.

7. Bauer, T. K. \& Bender, S., 2002. Technological Change, Organizational Change,. IZA Discussion Paper, Issue 570.

8. Benghozi, P.-J. \& Cohendet, P., 1997. L'organisation de la Production et de la Décision face aux TIC. Dans: Rapport $d u$ Commissariat Général du Plan. s.l.:s.n.

9. Black, P., Harrison, C., Lee, C. \& Marshall, B. a. W. D., 2003. Assessment for learningputting it into practice. Maidenhead, U.K.: Open university Press.

10.Black, S. E. \& Lynch, L., 2001. How to compete: the impact of workplace practices and information technology on productivity. The Review of Economics and Statistics, 83(3), pp. 434-445.

11.Boughzala, M., 2013. Youth employment and economic transition in Tunisia". Global Economy and Development, Working Paper, Issue 57.

12.Bresnahan, T. F., Brynjolfsson, E. \& Hitt, L. M., 2002. Information technology, workplace organization and the demand for skilled labor: firm-level evidence. Quarterly Journal of Economics, 117(1), pp. 339-376.

13.Brotcorne, P. \& Valenduc, G., 2009. Les compétences numériques et les inégalités dans les usages d'Internet. Comment 
réduire ces inégalités?. Les Cahiers $d u$ Numérique, 5(1), pp. 45-68.

14.Bué, J., Guignon, N., Hamon-Cholet, S. \& L.Vinck, 2002. Vingt ans de conditions de travail". Données Sociales- La société française, INSEE.

15.Calavrezo, O. \& Pelek, S., 2011. Qui sont les salariés payés au salaire minimum? Une analyse empirique à partir des données turques. Document de travail, Issue 139.

16.Card, D. \& DiNardo, J. E., 2002. SkillBiased Technological Change and Rising Wage Inequality: Some Problems and Puzzles. Journal of Labor Economics, 20(4).

17.Caroli, E. \& Reenen, J. V., 2001. Skill biased organizational change? Evidence from a panel of british and french establishments. Quarterly Journal of Economics, 116(4), pp. 1449-1492.

18.Chan, K., Zhou, X. \& Pan, Z., 2014. The growth and inequality nexus: The case of China. International Review of Economics \& Finance, 34(C), pp. 230-236.

19.Conte, A. \& Vivarelli, M., 2007. Globalization and Employment: imported Skill Biased Technological Change in Developing Countries. IZA Discussion Paper, Issue 2797.

20.Crifo, P., 2003. La modélisation du changement organisationnel : déterminants et conséquences sur le marché du travail. Actualité Economique, 79(3), pp. 349-365.

21.Deursen, A. v. \& Dijk, J. v., 2010. Measuring Internet Skills. International journal of human-computer interaction, 26(10), pp. 891-916.

22.Ghazali, M., 2009. Trade Openness and Wage Inequality Between Skilled and Unskilled Workers in Tunisia. Économie internationale, Issue 117, pp. 63-97.

23.Greenan, N., 1996. Progrès technique et changement organisationnel: leur impact sur l'emploi et les qualifications. Economie et Statistiques, Issue 298, pp. 35-44.

24.Greenan, N. \& Walkowiak, E., 2005. Informatique, Organisation du travail et
Interaction sociales. Economie et Statistiques, Issue 387.

25.Haan, J. d., 2003. IT and Social Inequality in the Netherlands. IT \& Society, 1(4), pp. 27-45.

26.He, H. \& Liu, Z., 2008. Ivestment-specific technogical change, skill accumulation, and wage inequality. Review of Economic Dynamics, 11(2), p. 314-334.

27.Henderson, D. J., Qian, J. \& Wang, L., 2015. The inequality-growth plateau. Economics Letters, 128(C), pp. 17-20.

28.Howitt, P. W. \& Mayer-Foulkes, D., 2002. R\&D, Implementation and Stagnation: A Schumpeterian Theory of Convergence Clubs. NBER Working Paper Series, Issue 9104.

29.Iniguez-Montiel \& Javier, A., 2014. Growth with Equity for the Development of Mexico: Poverty, Inequality, and Economic Growth (1992-2008). World Development, Volume 59, pp. 313-326.

30.International Monetary Fund, 2014. Redistribution, Inequality and Growth, s.l.: s.n.

31.Mincer, J. A., 1974. Schooling, Experience, and Earnings. New York: Columbia University Press for the National Bureau of Economic Research.

32.0CDE, 2014. Focus - Inégalités et croissance-décembre 2014, s.l.: s.n.

33.Quinet, A., 2000. Nouvelles technologies, nouvelle économie et nouvelles organisations. Économie et Statistique, Issue $339-340$, pp. 3-14.

34.Saafi, S., 2012. Effets des Innovations Technologiques sur L'emploi Industriel: Essai D'analyse à Partir du Cas Tunisien, France: Université du Littoral-Lille Nord de France.

35.Winchester, N. \& Greenaway, D., 2007. Rising wage inequality and capital skill complementarity. Journal of Policy Modeling, 29(1), p. 41-54. 